\title{
Medical Quackery In Nigeria: Why The Silence?
}

\author{
Ndububa V. I. MBBS, FMCOG, FWACS \\ Department of Obstetrics \& Gynaecology, College of Medicine and Health sciences, Imo State University, \\ Owerri, Nigeria.
}

\begin{abstract}
Background: This paper examines the magnitude and scope of medical quackery practice in 21st Century Nigeria and wonders why there is so much complacency in tackling the problem. It also proffers solutions to the malady.

Methods: Definition and brief history of medical quackery both in the developed world and Nigeria is given. The scope of the practice in Nigeria is then examined.

Results: Medical quackery is rampant in Nigeria; Culprits cut across the whole strata of medical and health practitioners. The so called alternative /natural health practice has particularly assumed great popularity lately and the Federal Government seems to turn the other way in spite of their unsubstantiated, largely placebo 'Cures'. Homeopathy, in particular, is a medical quackery per excellence and should be banned.

Law Enforcement Agents, Medical Practice Licensing Board and other Health Professions Licensing Boards, Nigeria Medical Association and other Health Profession Associations should take this problem seriously. Legislations should be made where they have not been made and enforced where they have been made and various professional bodies should not hesitate to sanction their erring members who deviate from acceptable practice.

The government will also do well in addressing the key problems of poverty and illiteracy as these are twin brothers that promote the practice and acceptance of medical quackery.
\end{abstract}

Conclusion: Unless concerted efforts are taken by all stake holders, especially the government, in tackling the health care problems in Nigeria, the decay in the system will continue and medical quackery will continue to thrive.

Keywords: Quackery; Nigeria; Stakeholders

Paper accepted for publication 5th September 2007

\section{INTRODUCTION}

Medical quackery is a term used to describe the provision and dispensation of false medical advice or treatment. It entails the unethical practice of promising health-related benefits for which there is little or no scientific basis.
Stephen Barrett of "Quack Watch"1 defined health quackery as anything involving over promotion in the field of health. This will include questionable ideas and questionable products and services regardless of the sincerity of their promoters.

This definition aptly describes the present malady in Nigeria where our magazines and national dailies are replete with advertisements of "all curing" remedies, promoted by natural and alternative medicine practitioners and nobody seems to question these, essentially, charlatans. In addition to the ethical problems of promising benefits that cannot reasonably be expected to occur, quackery also includes the risk that patients may choose to forgo treatments that are more likely to help them.

Medical quackery has existed throughout human history. In the Western world, widely marketed quack medicine (patent medicines) first came to prominence during the 17th and 18th centuries in Britain and British colonies, including those in North America. ${ }^{2}$ The later years of the 18th century saw an increase in the number of internationally marketed quack medicines, the majority of which were British in origin. ${ }^{3}$

In the USA false medicines from the early 19th century were often denoted by the slang term "snake oil" and those who sold them were termed 'snake oil peddlers". Some of these quacks in USA became enormously rich, just like some now in Nigeria. For example, William Radam who in 1880s, started to sell his 'Microbe Killer' throughout the British Colonies. His concoction was widely advertised as being able to "cure all diseases" . His medicine was essentially dilute solution of sulphuric acid coloured with little red wine. ${ }^{5}$

It seems our own quack practitioners are doing what theirAmerican counter parts did two centuries ago!

The end of the road for the quack medicines practitioners in America and Europe came in the early 20th Century. February 21st, 1906 saw the passage into law of the Pure Food and Drug Act in USA. This 
was the result of decades of campaigning by both government departments and the medical establishment supported by a number of publishers and journalists.

In Nigeria, it is difficult to ascertain the origin of medical quackery but this certainly predated the colonial era when native doctors or traditional healers were the sole health care providers. These practitioners often mix native herbal and root remedies with spiritual divinations and incantations and when their treatments failed to obtain the desired results they attribute the failure to the wrath of the gods! Though some of their herbal medicines could have genuine curative properties but because there were no checks and balances, efficacy could not be proven and some could have been harmful as a result.

With the advent of Western Civilization, the raw 'native doctor' practice has now taken the backstage.

What we have now is a deluge of "modern native doctors" who hide under the guise of alternative medicine practitioners, herbal medicine practitioners or trado medicine practitioners, whatever that means. The practitioners of this trade range from pure illiterates to well educated ones, some claiming to have PhD.

One common feature of these groups of quacks is that they all claim to have remedies for virtually every ailment including witchcraft and bad luck! Some apparently mixing herbal medicine with voodoo.

The more educated ones are however becoming more innovative with their herbal medicines now in tablet and capsule forms and well packaged. Some of them even have National Agency for Food and Drug Administration and Control (NAFDAC) numbers. Whether the latter are genuine is another thing. It is very doubtful if any of these herbal medicines had undergone any scientifically approved drug trials before they were pushed into the market. NAFDAC needs to be commended for its efforts in checking the circulation of fake and adulterated drugs especially the orthodox drugs. I think NAFDAC should also focus more attention on these herbal preparations. Unfortunately, in 21st century Nigeria, medical quackery is not limited to herbal medicine practitioners. Many orthodox health professionals are also culprits, their modus operandi range from medical officers feigning as specialists and thus giving substandard care, to other orthodox health professional guilty of playing the doctor.

The homeopathic medicine practitioners are particularly dangerous and shall receive special attention in this article. They are predominantly seen in the rural and semi- urban areas of South East Nigeria.

\section{THE SCOPE OF MEDICAL QUACKERY IN NIGERIA}

Medical Quackery among Medical Professionals (Orthodox Medical Doctors)

Sadly enough, medical doctors are not exempted from medical quackery. The most pervading form of this seems to be the malpractice of non-specialist doctors acting as specialists. Relying on some specialist skills they acquired while working in a general hospital or mission hospital, they 'open shop' and start practicing as specialists. Some of the more ambitious ones go abroad and obtain a one year diploma (for example a diploma in Obstetrics \& Gynaecology) and start practicing as a certified Obstetrician and Gynaecologist. I personally know an experienced medical officer in a popular private hospital who has converted to a consultant Obstetrician and Gynaecologist (with the label 'Consultant Obstetrician \& Gynaecologist' boldly written on his consulting room) without any formal training or certification!

Sometimes, junior residents are hired by mission hospitals as specialists. There was this case of a junior resident, known to me, who was less than a year in the residency programme but hired by a mission hospital as visiting orthopaedic surgeon. When his HOD went to the same hospital to ask for a placement as their visiting consultant orthopaedic surgeon, he was told by the hospital administrators that they had one already. On further enquiry, he discovered their visiting orthopaedic surgeon was his junior resident!

Examples abound but suffice it to say that the end-point is that the patients suffer and the respect for the profession is watered down. The clients receive suboptimal care for the purported specialist care they are given and, so, can be said to have been defrauded-a form of health fraud which entails deliberate deception.

Other forms of quackery practiced by some medical doctors are over- diagnosis and over-treatment of typhoid fever (often as a result of reliance on the dubious Widal test and inadequate treatment of malaria), too much emphasis on injections, polypharmacy (I have seen some private practitioners prescribe 8 drugs at the same time!) and apparent easy resort to appendicectomy. I did a personal study (not published) in the South East of Nigeria where I found that $12 \%$ of my antenatal clients have had appendicectomy! This is rather unjustifiable and borders on criminality considering the known incidence of acute appendicitis quoted in popular literature. For 
example, Badoe et al ${ }^{6}$ quoted acute appendicitis incidence of 1 in 789 in England and Wales and 1 in 3333 in Accra, Ghana.

Many of those surgeries were, apparently, cases of commercial medicine. This, just like the aforementioned malpractices, is nothing short of medical quackery, going by the earlier definition of medical quackery, and mechanisms must be put in place to check these.

\section{Medical Quackery Among Other Health Professionals}

The other health professionals included in this category are the pharmacists, medical laboratory scientists, nurses and radiographers. I think the bane of this other health professionals is playing the doctor's role syndrome. It is a common practice in Nigeria that pharmacists do not only dispense drugs but also prescribe. This is particularly so in privately owned pharmacy shops. Some of them have adjoining consulting rooms where clients are consulted, drugs prescribed and administered in some cases.

Medical laboratory scientists and nurses are particularly guilty of playing the doctor. Very often, the former does not limit himself to conducting laboratory tests but go ahead to make diagnosis and prescribe drugs based on his lab results that are often spurious. Two notorious diagnoses they make for which they prescribe drugs are typhoid fever and staph aureus infections based on dubious widal test and swab test results (apparently from skin contamination) respectively.

It is a common practice in Nigeria that outside the organized health facilities, nurses often feign as doctors making diagnosis and prescribing drugs. This is particularly so in the rural areas where the male nurses are often mistaken as doctors and they do not hesitate to hide their true identities from their clients. Some of them open clinics and operate as medical doctors. Midwives open maternities and manage both low risk and high risk antenatal patients without any check, incurring unnecessary maternal and perinatal mortalities and morbidities.

Examples abound of pregnant women who were mismanaged in such maternities who shouldn't have been managed in such centers in the first place - a pure example of medical quackery.

Alternative Medicine Practitioners (Including Homeopaths)

As mentioned earlier in the introduction, the fallout of modernization has pushed the original native doctor practitioners to the background and the alternative medicine practitioners of today can be said to be their modern equivalents.

This group of health practitioners seem to have gained popularity in the past ${ }^{12}$ decades in Nigeria because of the relative cheapness of their medications (compared with the increasing cost of obtaining orthodox health care in Nigeria) and also because of their notorious claims of being able to offer cures for virtually every ailment. Many times, I have attended to women with huge uterine fibroids who have used such herbal preparations without any benefits and have ended up undergoing myomectomy or hysterectomy. Many of our national dailies and magazines advertise these spurious claims and we all seem to have accepted them and they even have advocates in many quarters. I am not saying that herbal medicine cannot be beneficial but should we accept such preparations without scientific trials and evidence based proofs? The danger I foresee, which we are already seeing, is that we shall increasingly be seeing the advanced stages of ailments which would be better managed if they had expert orthodox treatment from the onset.

\section{HOMEOPATHIC MEDICINE PRAC-TITIONERS}

Homeopathic medicine probably first came into national limelight about 2 decades ago when a certain Sylvester Ugo, a homeopathic medicine practitioner, claimed to have achieved the first test tube baby birth in Nigeria. His claims were investigated by the Federal Ministry of Health, headed by the late Prof. Olikoye Ransome-Kuti, and his claims were then found to be spurious. For those who didn't know, this saga probably gave the first clue to the medical fraud called homeopathy. A short history and practice of this 'fraud' will probably throw more light on this.

The word "homeopathy" is derived from the Greek words homoios (similar) and pathos (suffering or disease). Samuel Hahnemann (1755-1843), a German physician began formulating homeopathy's basic principles in the late $1700 s^{7}$. He was justifiably distressed about blood letting, leeching, purging and other medical procedures of his day that did far more harm than good. Thinking that these treatments were intended to "balance the body's 'homors' by opposite effects", he developed his "law of similars" a notion that symptoms of disease can be cured by extremely small amounts of substances that produce similar symptoms in healthy people when administered in large amounts. 
Apparently in line with this spurious belief, some homeopathic manufactures market highly diluted mineral products called "cell salts" or "tissue salts" which are claimed to be effective against a wide variety of diseases including appendicitis (ruptured or not!) baldness, insomnia and worms. Their use is based on the motion that mineral deficiency is the basic cause of disease. However, many are so diluted that they could not correct mineral deficiency even if one was present.

It is interesting to note that homeopathic remedies have been subjected severally to scientific trials without any benefit seen better than placebo. In 1990, an article in Review of Epidemiology ${ }^{8}$ analyzed 40 randomized trials that had compared homeopathic treatment with standard treatment, a placebo or no treatment and the authors concluded that there is no evidence that homeopathic treatment has any more value than a placebo. Just like herbal medicine practice, 'cure', If any, in homeopathy (sometimes it is difficult to separate the 2 practices) seems to be based on placebo effect. Placebo effects can be powerful of course, but the potential benefit of relieving symptoms with placebos should be weighed against the harm that can result from relying upon and wasting money on ineffective products.

In Nigeria today, homeopathic medicine is predominantly practiced in South East Nigeria where they have permeated most of the rural areas. They are particularly common in what I will call 'Orlu-Oguta-lhiala axis'; there is even a Homeopathic Teaching Hospital in Oguta, Imo State!

Several times, I have attended to patients who told me they had seen some other doctors who diagnosed their ailments using computers placed on their arms. On further questioning, I discovered that the so-called doctors were homeopaths. It is amazing that neither the government nor any licensing body seems to have any control on their practice and it is business as usual for them.

\section{UNSKILLED HEALTH PRACTITIONERS}

The traditional native doctors, traditional bone setters, patent medicine sellers and Traditional Birth Attendants (TBAs) all fit into this group. They all have one thing in common they never had any formal and regulatory training although most had one form of apprenticeship or the other. In addition, they are mostly found in rural areas. Not under any regulation, they are let loose into the society, perfecting medical quackery.

The traditional native doctor mixes herbal medicine with spiritual healing with a heavy dose of incantations, often no dividing line between the natural and the spiritual and, at such, their practice cannot be subjected to scientific inquest. Even though most of these practitioners are ill-educated, they have answers to all ailments.

The traditional bone setters are presently preying on orthopaedic surgeons. It seems to me that most orthopaedic patients in the rural areas visit these traditional bone setters first until they are compelled by complications to be referred to orthodox practitioners. The majority of the rest go home with life long deformities resulting from mismanagement. The pertinent question is: why do these patients flock to them? I shall attempt to answer this question later.

The patent medicine shop owners are ubiquitous both in rural and urban areas of Nigeria but operate more with impunity in the former. More often than not, they consult, prescribe and administer drugs to their clients! They are also notorious for procuring unsafe abortions. They are major outlets for fake and adulterated drugs. It seems to me that the Nigerian Pharmacists and the relevant regulatory bodies have given up on checking this group of health quacks, living the majority of helpless sick Nigerians at their mercy.

Although the population and the role of TBAs is not as much as it used to be during the pre-colonial and colonial era due to increasing number of orthodox trained midwives produced in Nigeria over the years, their role cannot be said to be insignificant especially when one considers the fact that in Nigeria, only $20 \%$ of mothers are said to have access to antenatal care ${ }^{9}$. This means that majority of our women, especially in rural areas, have their pregnancies and deliveries managed in unorthodox centers mainly manned by these TBAs. Lacking basic knowledge in anatomy and physiology of pregnancy and labour, they manage our pregnant women according to their own understanding, incurring unacceptable levels of both maternal and perinatal mortalities and morbidities in the process. For a long time, there has been a controversy whether TBAs should be formally trained or not without any consensus yet arrived at so that up to the time of this write up, the TBAs have been left to practice as they deem fit, unchecked!

In the recent past, it seems many of these traditional birth centers are now turning into faith centers commonly called Mission House in South West Nigeria. 
In these mission houses, faith and prayers are the 2 essential instrument of work with little or no facilities for essential obstetric care. Many times, in such mission houses, women with 2 or more previous caesarian deliveries are made to go through labour only supported by faith and prayers.

\section{THE WAY FORWARD}

For there to be any meaningful change in the present appalling state of medical quackery in Nigeria the medical professionals must first put their houses in order.

Doctors need to re-orientate themselves and the incoming doctors in different medical schools must be orientated that medical practice is a calling to serve humanity and not just a means to make money. This is not to say that a doctor cannot open a hospital with the intention to make money but honest service and sound medical practice should not be sacrificed for financial gains. I suggest that our different medical faculties should come out with medical curriculum that lays more emphasis on medical ethical practice and sound character development than it is now. It seems more emphasis is placed on acquiring theoretical knowledge and clinical skills with little attention paid to producing doctors of good character and who are well tutored in good doctor patient relationship.

The Nigerian Medical and Dental Council (NMDC) in collaboration with Nigerian Medical Association should institutionalize the issue of medical update courses for medical practitioners especially for non-specialists and those in private practice. And only those who attended specific number of such update courses should have their practice licenses renewed. This will reduce medical quackery and substandard practice. Up till now, only lip service has been paid to this important issue of continuous re-training of doctors. No structure is yet on ground to sustain this. The NMDC should also intensify its disciplinary actions on medical practitioners who display woeful medical practices, not short of medical quackery.

Although, I am not vast in the training programmes of other health professionals, I think they are trained to practice within the limits of their specializations. If that is the case, then the present tendency of this group of health professionals to play the doctor must be considered unethical and nothing short of medical quackery per excellence.
The relevant regulatory bodies should sanction such erring practitioners who, for example, consult, carry out tests, diagnose and prescribe for patients! If this is not regarded as quackery and unethical by the concerned regulatory bodies, the practice will continue unabated.

Alternative/Herbal medicine practice is presently thriving in Nigeria mainly because of the prevailing poverty in the land and the resultant increasing cost of obtaining orthodox medicine and so the people are resorting to alternatives to orthodox medicine. Another possible reason why alternative medicine is becoming popular in Nigeria could be because, having been disappointed many times by orthodox practitioners whose practice borders on quackery, many clients have become disillusioned and are now turning to alternative medicine. Addressing poverty and encouraging sound medical practice will therefore largely curtail alternative medicine practice. In addition, the governments at all level should show more commitment in regulating alternative medicine practice. The claims they ascribe to some of their products are laughable and should not be taken lightly. Although majority of their herbal products may not be directly harmful to health ,the danger is that patients who have ailment, sometimes with life threatening potentials, that will benefit more from orthodox medicine are diverted to such herbal preparations that have no more benefit than placebo, with dare consequences.

I recommend that homeopathic medicine should be banned in Nigeria because it has no scientific basis but rather medical quackery per-excellence. Clandestine practice will, however, continue if the government does not address poverty and improve health care delivery.

Legislation against native doctors, traditional bone setters, TBAs and the ubiquitous chemists would probably not work as long as the government does not provide easily assessable alternatives and poverty not alleviated. When the people are economically empowered and modern health care services are made easily available and affordable, the traditional bone setters and their brothers in quackery will die natural death.

The role of government at all level cannot be overemphasized. Presently, the Federal Government is at advance stage of incorporating traditional/herbal health care providers into the mainstream national health programmes. Patriotic as this may appear, the pertinent question is: has the government done enough research 
to show that this policy will benefit health care in Nigeria? I very much doubt if these herbal products with their grandiose laughable claims can advance our health care unless we want to resign ourselves to mediocrity. Let us not incorporate herbal medicine into our health programme just because that will promote our African heritage but only those that stand the test of scientific trials should be encouraged. Simple.

The issue of poverty alleviation has already been mentioned. I want to stress that this is an area that the government needs to show more commitment and not rhetoric. Many clients will continue to patronize quacks as long as they don't have the economic wherewithal to seek optimal medical care. The National Health Insurance Scheme (NHIS) is laudable but its implementation is still fraught with bottlenecks. The masses seem to be sidelined in its implementation.

Finally, there is urgent need for the government to upwardly review the remuneration of doctors and other health professionals. A well paid health professional is less likely to cut corners and resort to quackery. The truth is that the average Nigerian doctor today feels under paid with poor conditions of service and poor health facilities for optimal medical practice resulting in many of them leaving the country in droves. The remaining ones try to make ends meet sometimes by engaging in unethical and quack practice. The government, at all levels, showing serious commitment to improving the remunerations and conditions of service of health professionals is therefore an important step to take in checking the present rot in our health care system.

\section{CONCLUSION}

It is saddening that in the 21st Century Nigeria, medical quackery practice is high and widespread much as it was in 19th Century America! The unorthodox health practitioners are having a field day. It is painful that even many orthodox practitioners are not exempted. And what is more saddening is that it seems the government and other stake holders in the health care system in the country are just not doing enough. We all seem to be helpless, but there can be a way out. The NMDC and other health professions regulatory bodies should pay more attention to the quality of their professionals than just collecting annual practicing dues. The government and the leadership of this country must change from their present inept leadership where transparency and meritocracy are relegated to the background in favour of nepotism and graft. This has been a major reason for the country remaining poor and poverty promotes both patronage and practice of medical quackery. The need to improve the remunerations and the conditions of service of health professionals cannot be over emphasized.

\section{References}

1. WWW. Quack watch. org/01 Quackery Related Topics/quack definition (Assessed on 1/7/2006)

2. Styles J. Product innovation in early modern London. In: Past and Present, 2000: 124-169

3. Griffenhagen K, George B, James Harvey Young. "Old English Patent Medicines in America" Contributions from the Museum of History and Technology, US, National Museum Bulletin, Washington: Smith Sonia Institution, 1959;218:155-83

4. Radam W. Microbes and the Microbe Killer, Privately Published. New York; 1890: 369

5. Young JH. The Toad stool Millionaires: A social history of patent medicines in America before federal regulation. Princeton University Press, 1961: 282

6. Badoe E.A. Archampong EQ, da Rocha Afodu JT. The appendix In: Principles and Practice of Surgery including Pathology in the Tropics 3rd edition. Tema Ghana Publishing Corporation, 2005: 518-528.

7. Stephen Barreth November, 2003 Homeopathy: The ultimate Fake http: // WWW. Quack watch. org/01Quackery Related Topics/Homeo. html.

8. Hill C, Doyen F. Review of randomized trials of homeopathy. Review of Epidemiology, 1990; 38: 139-142.

9. UNAIDS. Dec 2001 AIDS Epidemic update. http: //WWW unaids. org. 